\title{
Editorial
}

\section{Tonia Gray}

"Deadline" ... have you ever wondered about the origins of this word? Could it be that we are literally "dead" once you reach this arbitrary cutoff date? Somehow, this notion rings true with me. This issue has been difficult to get to the printery for two reasons: firstly, so much seems to have happened in recent political world events. As a result, the "extraordinary" makes the "ordinary" things in our lives pale in significance. When the news broke about the acts of terrorism in the USA, I was in the middle of a six-day wilderness expedition with ten young Americans. Our transition back into the "real world" was like nothing I have ever experienced before. In particular, the underlying xenophobia and the privileging of one life over another, has left me questioning humanity.

Secondly, I have come to the realization that after nearly four years of being associated with the AJOE, the time has come for me to hang up my editorial hat. After Vol 6 No 2 it will be time to hand over the reins to the new incumbent. Quite honestly, I don't know whether I have lost the editorial passion, or whether the demands of my "real-daytime job" have escalated to a frenetic level. But whatever the case, the bottom line is that I'm wrestling with the challenge of getting my life in perspective. I need to prune some of my responsibilities - and it is with reluctance that $\mathrm{I}$ have chosen to relinquish this position.

Nonetheless, the collection of articles in this edition of AJOE is testimony to the superb standard of writings taken from around the globe. Firstly, the thought provoking paper by Hovelynck explores the concept of "how much space is there for the learners' experience in so-called experiential education?" (pg. 11). In other words, how much does the facilitator mould or contrive the outcomes of an experience? In simplistic terms, thou "shall learn what I want you to learn" rather than learning what you inherently need to learn. This opens Pandora's Box with respect to the ethical implications of the facilitator's input colouring the outcomes of the experience. Readers may find themselves re-evaluating their modus operandi as a result of this article.

From my perspective, burnout appears to be endemic within our profession. In particular the paper by Thomas highlights some of the human resource management issues and offers "some hope for practitioners seeking to maintain their involvement with that profession" (pg. 24).

Riding on the wave instigated by our recent National Conference in Bendigo, A Sense of Place, it could be extrapolated that indigenous teachings and self and place are inextricably linked. For those of us searching for ways of developing a deeper relationship with place, Birrell takes us through a step-by-step method of developing intimacy with place. Indeed, many outdoor educators could benefit from incorporating some of these indigenous notions into their teachings - one which moves "towards a more authentic, visceral relationship with the earth and all its beings" (pg. 30).

Dickson's article eloquently discusses a risk score formula developed 30 years ago and demonstrates its potential use in calculating risks in an outdoor and experiential learning environment. However, she cautions that a "risk score formula does not eliminate risks, it does, however, provide a mechanism for ranking various risks that will enable resources to be most effectively and efficiently allocated to ensure that the most urgent and severe risks are given highest priority" (pg. 36).

Wilderness-enhanced programs have much to offer special populations. A longitudinal $\mathrm{PhD}$ study an behaviour-disordered adolescents is summarized in Brand's paper. This exemplary research confirms what many outdoor educators already knew - the wilderness is a sacred place and space - and instigates functional change in participants. Paradoxically, the program under investigation has been scaled down by the NSW Department of School Education. One is left wondering "why" these random cutbacks occur given the irrefutable success highlighted in Brand's study.

Neill and myself review the first five years of the AJOE. From a historical perspective, the articles to date have been on articulating and applying theory about outdoor education, with significant focuses also on research and practice. A breakdown of authorship taking into account gender and place of employment provides some interesting findings.

Lastly, in the non-refereed section, Collard takes us through the trial and tribulations of "adventure in the courtroom". Ironically, this is something near and dear to many hearts given the increasingly litigious nature of society. Dickson's second paper offers some practical and useful tips in the Facilitator's Notebook section. Finally, I urge readers to look at Stanton's book review as it provides indigenous perspective on this controversial topic.

Happy reading over the upcoming summer.

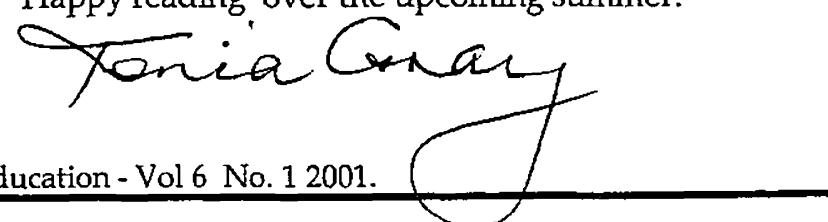

